\title{
James Watson's genome sequenced at high speed
} one-quarter as far in today's polluted city air as it did two centuries ago, according to a University of Virginia study. Perhaps this is one cause of sharply declining bee populations.

Fragrant spring breezes The fragrance of flowers travels only around discharges in thunderclouds using lasers.

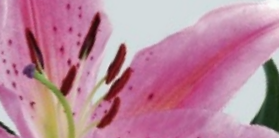

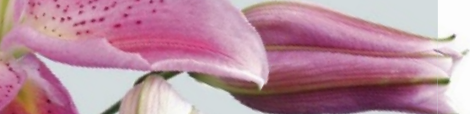

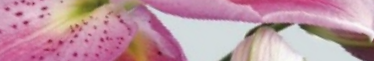

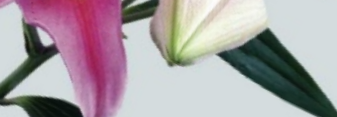

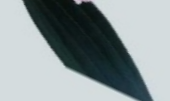

\section{NUMBER CRUNCH}

960 is the number of significant 'natural hazard losses' - events often more colourfully described as 'acts of God' - in 2007, according to figures compiled by German insurance firm Munich Re.

\section{US\$ 82 billion is the total}

financial cost of these events, of which the insurance industry repaid around $\$ 30$ billion.

49 fatalities occurred in the most financially costly event, Europe's Winter Storm Kyrill. The deadliest event, Cyclone Sidr in Bangladesh, cost only one-third as much, but claimed more than 3,000 lives.

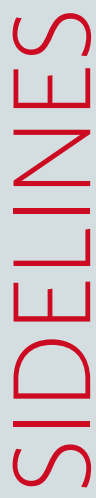

\section{ROBOT NEWS}

\section{Gender watch}

Japanese company Omron has developed a system that allows security cameras to tell the difference between male and female faces automatically. It could lead to even more targeted snooping into shoppers' habits.
The first full genome to be sequenced using next-generation rapid-sequencing technology is published today (see page 872$)^{1}$, marking another milestone in the extraordinarily fastmoving field of human genome sequencing.

It took just four months, a handful of scientists and less than US\$1.5 million to sequence the 6 billion base pairs of DNA pioneer James Watson. The achievement is first proof of principle that these rapid-sequencing machines can decipher large, complex genomes (see page 819$)^{2}$. Made in this case by Connecticut-based 454 Life Sciences - a division of Roche Diagnostics - they allow many more sequencing reactions to proceed at the same time, on the same surface, than the previous generation of machines that produced the inaugural human genomes ${ }^{3,4}$. That change has had big pay-offs in speed, efficiency and, ultimately, cost (see table).

James Watson's is not the first full genome to be published; that distinction goes to genomics entrepreneur J. Craig Venter, whose genome was sequenced using previous-generation machines ${ }^{5}$ at a cost of $\$ 100$ million. "Venter's genome was at the end of the last generation," says 454 founder Jonathan Rothberg of the Rothberg Institute for Childhood Diseases in Guilford, Connecticut, who is the Watson paper's lead author. "We did this work in January 2007, with last January's technology," he points out; the raw data were released in May 2007. "It just keeps on getting better and cheaper." Rothberg calls Watson "the first of the rest of us", but the low cost the team managed is still a far cry from the ' $\$ 1,000$ genome' challenge set by the X Prize Foundation.

Not everyone agrees the method is better. "It's a new standard of sequencing technology," says Venter. "But I don't think it's a new standard of genome coverage and independent assembly."

One concern is that rapid-sequencing methods cut DNA into much shorter snippets (in this case, 250 bases) for decoding than the old method used by the international Human Genome Project (HGP) and Venter's former company Celera for their 2001 sequences. These used 500-1,000-base snippets. Shorter snippets make reassembly more technically challenging and mean it is harder to probe areas of the genome that have large, repeating sequences.

Evan Eichler, a geneticist at the University of Washington in Seattle, notes that $5-10 \%$ of the genome consists of these complex areas, which contain disease-causing genes and vary widely among individuals. "My concern specifically is whether short-sequence technology will give us any information in those areas," Eichler says. "How much do we understand about these particular regions in Jim Watson's genome?"

Others point out that the authors on the Watson paper relied heavily on the HGP reference sequence, which they used as a guide to help them reassemble the snippets. "This paper certainly seems to be proof that they can do a good job with the 454 sequencing when they have a reference genome," says Jonathan Eisen, an evolutionary biologist at the University of California, Davis, who wants to use the machines to sequence other species. "Their next task will be to show that they can do a good job when they have no reference genome."

Despite all the sequencing advances, very little is known about how to read the book of life that is opening before us, says Michael Egholm, vicepresident of research and development at 454. Egholm was part of a counselling session advising Watson on the meaning of the 20 mutations in his sequence that are reported to be associated with increased disease risk. "It was so profound, how little we were actually able to say [to him] about that," he says. "To me, it really proved that this is the beginning, not the end."

\section{Meredith Wadman}

\footnotetext{
1. Wheeler, D. A. et al. Nature $452,872-876$ (2008).

2. Olson, M. V. Nature 452, 819-820 (2008).

3. The International Human Genome Mapping Consortium Nature 409, 934-941 (2001).

4. Venter, J. C. et al. Science 291, 1304-1351 (2001)

5. Levy, S. et al. PLoS Biol. 5, e254-e286 (2007)
}

QUICKER, SMALLER, CHEAPER

\begin{tabular}{|l|c|c|c|}
\hline Genome sequenced (publication year) & HGP (2003) & Venter (2007) & Watson (2008) \\
\hline Time taken (start to finish) & 13 years & 4 years & 4.5 months \\
\hline Number of scientists listed as authors & $>2,800$ & 31 & 27 \\
\hline Cost of sequencing (start to finish) & $\$ 2.7$ billion & $\$ 100$ million & $<\$ 1.5$ million \\
\hline Coverage & $8-10 \times$ & $7.5 \times$ & $7.4 \times$ \\
\hline Number of institutes involved & 16 & 5 & 2 \\
\hline Number of countries involved & 6 & 3 & 1 \\
\hline
\end{tabular}

